\title{
ANALYTICAL HIERARCHY PROCESS (AHP) FOR SELECTION OF RESIDENTIAL PLACE
}

\author{
S.S. Kuber \\ Associate Professor, Industrial and Production Engineering Department, \\ Vishwakarma Institute of Technology, Pune, India

\section{R.S. Bharsakade} \\ Assistant Professor, Industrial and Production Engineering Department, \\ Vishwakarma Institute of Technology, Pune, India

\section{Kartik Ramesh} \\ Department of Production Engineering, \\ Vishwakarma Institute of Technology, Pune, India
}

\begin{abstract}
In the process of selecting homes for residential use various factors play an important role. In our study, we are considering people working in the software industry in Pune City. People working with software companies mostly prefer homes in environment friendly locations. In the house selection process people evaluate several alternatives to make their decision. In our paper, we have proposed a systematic way of evaluating the alternatives using AHP.
\end{abstract}

Keywords: AHP, MADM, House selection.

Cite this Article: S.S. Kuber, R.S. Bharsakade and Kartik Ramesh, Analytical Hierarchy Process (AHP) for Selection of Residential Place, International Journal of Industrial Engineering Research and Development, 8(1), 2017, pp. 1-8. https://iaeme.com/Home/issue/IJIERD?Volume=8\&Issue=1

\section{INTRODUCTION}

Multi-criteria decision-making (MCDM) plays a critical role in many real life problems. A number of day to day decisions such as which school to take, which place to live, which clothes to use, which person to have as our best friend or to marry, which food to eat, which car to buy, and so on can be carried out using this method[4].

In this decision making method we make decisions by evaluating, prioritizing or selecting alternatives in the presence of multiple, usually conflicting criteria [2]. Multi-criteria decision making problems are classified into two broad categories that are Multi-Objective Decision Making (MODM) and MultiAttribute Decision Making (MADM).

MADM refers to making decisions [2] in a discrete decision space containing an elaborate description of the set of options and the characteristics involved in the evaluation process. Such difficulties are come across in many real-world situations, e.g. selection of a school. 
A long array of emerging technologies has opened up the potential for a variety of new products. The ever changing technologies of products cautioned the need for an equally quick response from the manufacturers or service providers [3]. The erstwhile model of 'unfocused, short-term views and nonholistic vision' is being replaced by the enlightened approach of 'focused, holistic and strategic vision'. To meet the challenges, manufacturers have to select the right manufacturing strategies, product designs, and manufacturing processes, work piece and tool materials.

Necessary conditions for achieving efficient decision making consists of understanding the current and upcoming events and factors influencing the whole manufacturing environment, in exploring the nature of decision-making processes and the reach of different typologies of methods and techniques, and finally in structuring appropriately.

\section{RESEARCH OBJECTIVES AND DEFINITION}

As the pollution level in many of the metropolitan cities is high, people prefer to have their homes in localities where there is less pollution. People have several constraints when purchasing a house. People not only look at the cost but the locality as well. Some quantum of quality is typically another factor that is in struggle with the price. While purchasing a house, price, environmental friendliness and infrastructure facilities are some of the primary factors we consider. Besides these factors, nearness to the workplace is also considered.

In our day to day lives, we evaluate numerous criteria unquestioningly and we may be satisfied with the results of such decisions that are made based on only intuition. On the other hand [5], when risks are high, it is necessary to properly define the problem and clearly evaluate multiple factors. While taking the decision of whether to construct a nuclear power plant or no, where to build it, there are not only very complex problems involving multiple conditions, but there are also various sections of society who are deeply affected [5].

MCDM has to do with the grouping and solving of decision and planning problems involving multiple criteria [7]. The principle is to aid decision makers' face such problems. Typically, there isn't a perfect solution for such problems and it is essential to make use of decision maker's desires to differentiate between solutions [4].

\section{METHODOLOGY}

\subsection{Data Collection}

For finding out the parameters based on which people usually select their houses, a questionnaire was prepared. Based on the questionnaire, the following parameters were obtained:

- Water supply

- Electricity

- Cost as per Budget

- Infrastructure Facilities

- Connectivity to other places in the city

- Nearness to work place

- Transport facilities available

- Pollution levels

- Surrounding

Out of all the above factors, the prime importance is being given for environment friendliness of the location while the other two factors being considered are cost per square feet and distance from the business centre.

The source for obtaining cost per square feet for particular location is obtained from Times Property. 


\subsection{Analytical Hierarchy Process (AHP) Model}

The analytical hierarchy process (AHP) is an analytical approach for formulating and analyzing intricate decisions, based on mathematics and psychology [4]. It was brought forth by Thomas L.Saaty in the 1970s and has been extensively studied and has been refined since then [4].

It is used in number of complex decision making situations by governments, businesses, and healthcare, shipbuilding, and education sectors.

Rather than laying down a "correct"[4] decision, AHP helps decision makers choose a solution that best suits their objective and their understanding of the problem. It provides a complete and balanced framework for designing a decision for the problem, for representing and describing its components, for relating those components to the overall objective, and for exploring alternative solutions.

Users of the AHP primarily break up their problem into echelons of more [4] comprehensible subproblems, each of which are examined independently. The components of the hierarchy can relate to any facet of the problem tangible or intangible, carefully examined or plainly estimated, and anything at all that applies to the decision at hand.

Once the echelons are built, the decision makers carefully examine the various components by comparing them with one another, with respect to their impact on the component above them in the structure [6]. While making comparisons, the decision makers can use specific information about the components, but usually they use their judgments about the components' relative meaning and importance [6]. It is the core of the AHP that human judgments, and not just the available information [4], can be utilized for evaluation purpose.

The AHP transforms these evaluations to numerical values that can be processed and compared over the entire range of the problem [4]. A numerical weight age or priority is established for each component of the hierarchy, allowing different and often distinctive elements to be compared to one another in a balanced and consistent way [6]. This attribute differentiates the AHP from other decision making techniques [4].

Here we calculate the distance from the place Hinjewadi (Pune) as a central base for setting up the new location for company.

\subsection{Steps in AHP}

The detailed steps which are carried in AHP are shown in flowchart 1. 


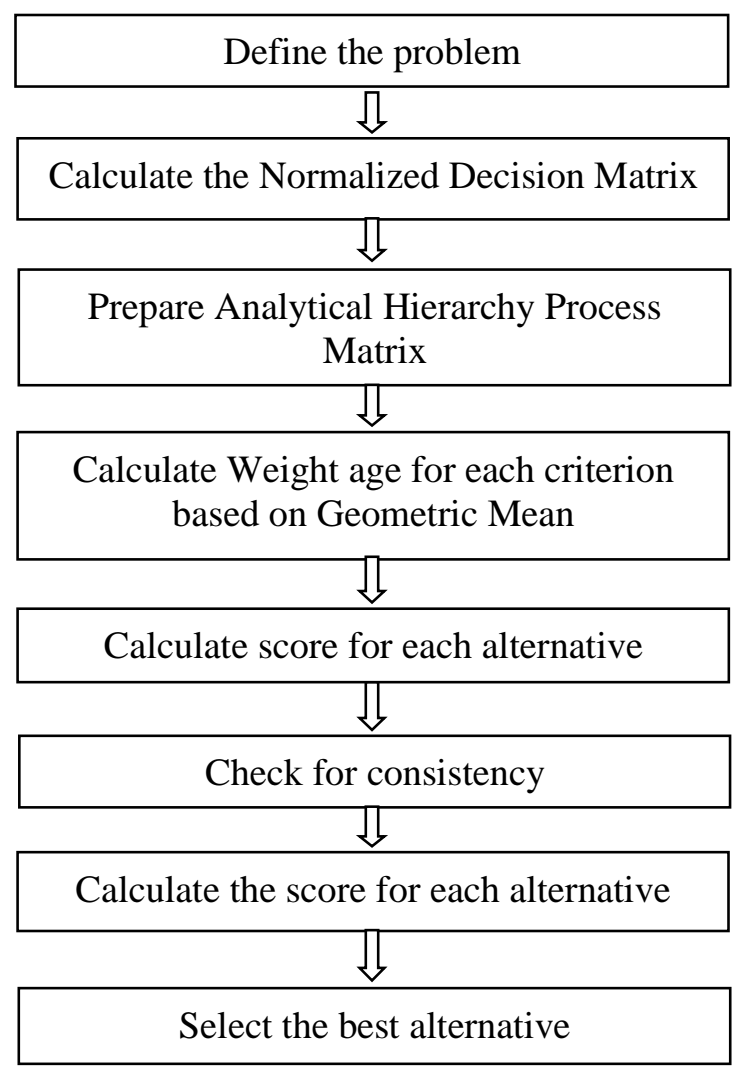

Figure 1 Flow Chart 1

\subsection{Calculations}

For the purpose of calculations, we have taken the business centre at Hinjewadi, Pune as most of the software companies are located in that area, and calculated the relative distance to various places where the residential places are located.

Table 1 Standard values of the various parameters to be considered for AHP

\begin{tabular}{|l|c|c|c|c|c|c|c|c|c|c|c|}
\hline & PM(2.5) & $\begin{array}{c}\text { PM(10 } \\
\text { ) }\end{array}$ & $\begin{array}{c}\text { NO } \\
\mathbf{2}\end{array}$ & $\mathbf{C O}$ & $\begin{array}{c}\text { Cost } \\
\text { sq ft } \\
\mathbf{( R s )}\end{array}$ & $\begin{array}{c}\text { Distance } \\
\text { from } \\
\text { business } \\
\text { centre(K } \\
\mathbf{m})\end{array}$ & Temp & $\begin{array}{c}\text { Humid } \\
\text { ity }\end{array}$ & Wind & Rain \\
\hline Katraj & 81 & 78 & 19 & 23 & 15 & 4948 & 30.3 & 33 & 49 & 2 & 0 \\
\hline $\begin{array}{l}\text { Shivaji } \\
\text { Nagar }\end{array}$ & 91 & 139 & 46 & 46 & 15 & 9461 & 17.3 & 33 & 49 & 2 & 0 \\
\hline Pashan & 79 & 100 & 38 & 19 & 23 & 8238 & 14.2 & 33 & 49 & 2 & 0 \\
\hline $\begin{array}{l}\text { Lohgao } \\
\text { n }\end{array}$ & 84 & 95 & 17 & 60 & 14 & 4150 & 28.5 & 33 & 49 & 2 & 0 \\
\hline Manjii & 81 & 78 & 19 & 23 & 15 & 4855 & 18.2 & 33 & 49 & 2 & 0 \\
\hline $\begin{array}{l}\text { Hadaps } \\
\text { ar }\end{array}$ & 101 & 114 & 34 & 67 & 20 & 6519 & 28.9 & 33 & 49 & 2 & 0 \\
\hline Alandi & 59 & 98 & 63 & 39 & 18 & 4820 & 27.2 & 33 & 49 & 2 & 0 \\
\hline
\end{tabular}


Table 1 gives the various gases such as carbon monoxide, nitrogen dioxide and particulate matter present in the atmosphere. The other parameters considered for the study are cost per square feet, distance from the business centre to the different residential zones in the city, temperature, humidity, wind and rainfall.

\subsubsection{Normalize the Given Table1}

Normalizing table1 gives the value for each alternative into one single scale i.e. Criteria for selecting the alternative based on cost, delivery speed, flexibility and easy availability. So this criteria for comparison needs to be one single scaling unit. We have scaled into (0-1) scale where 0 indicates the worst criteria for given alternative and 1 indicates the most likely and favorable criteria to given alternative.

Here we calculate the distance from the place Hinjewadi (Pune) as a central base for setting up the new location for company.

We have not considered alternatives like Temperature, Humidity, Wind and Rain because of same values for all alternatives.

Table 2 Normalized values of Table 1

\begin{tabular}{|l|c|c|c|c|c|c|c|}
\hline & PM(2.5) & PM(10) & O2 & NO2 & CO & Cost/sq ft & $\begin{array}{c}\text { Distance } \\
\text { from } \\
\text { centre }\end{array}$ \\
\hline Katraj & 0.7284 & 1 & 0.3016 & 0.8261 & 0.9333 & 0.8387 & 0.4686 \\
\hline $\begin{array}{l}\text { Shivaji } \\
\text { Nagar }\end{array}$ & 0.6484 & 0.5612 & 0.7302 & 0.4130 & 0.9333 & 0.2132 & 0.8208 \\
\hline Pashan & 0.7468 & 0.78 & 0.6032 & 1 & 0.6086 & 0.5037 & 1 \\
\hline Lohgaon & 0.7024 & 0.8210 & 0.2698 & 0.3167 & 1 & 1 & 0.4982 \\
\hline Manjri & 0.7283 & 1 & 0.3016 & 0.8261 & 0.9333 & 0.8548 & 0.7802 \\
\hline Hadapsar & 0.5841 & 0.6842 & 0.5397 & 0.2836 & 0.7 & 0.6366 & 0.4913 \\
\hline Alandi & 1 & 0.7959 & 1 & 0.4872 & 0.7778 & 0.8609 & 0.5220 \\
\hline
\end{tabular}

Table 2 gives the normalized values of all the parameters described in Table 1

\subsubsection{Analytical Hierarchy Process (AHP) Matrix}

Here we give the importance to the criteria as follows.

Cost \& oxygen are moderately important than PM (10) and Distances are strongly important than PM (2.5), NO2 and CO. PM (10) and Distances are moderately important than PM (2.5) and PM (10) and Distances are strongly important than NO2. PM (2.5) is moderately important than NO2 and strongly important than CO.NO2 is moderately important than $\mathrm{CO}$.

Table 1 Criteria for weight age

\begin{tabular}{|c|l|}
\hline Scale & \multicolumn{1}{|c|}{ Criteria for weight age } \\
\hline 1 & Cost of flat per sq. Feet, Oxygen content \\
\hline 3 & PM 10 content, Distance from Hinjewadi. \\
\hline 5 & PM 2.5 content \\
\hline 7 & NO2 content \\
\hline 9 & CO content \\
\hline
\end{tabular}


Table 3 gives the criteria for weight ages in ascending order assigned to the most significant parameters considered for this study.

Table 4 Represents AHP matrix scaling based on 'Criteria for Weight age'

\begin{tabular}{|l|c|c|c|c|c|c|c|}
\hline & O2 & PM(10) & PM(2.5) & NO2 & CO & $\begin{array}{c}\text { Cost per } \\
\text { sq ft }\end{array}$ & $\begin{array}{c}\text { Distance } \\
\text { from } \\
\text { business } \\
\text { centre }\end{array}$ \\
\hline $\mathrm{O} 2$ & 1 & 3 & 5 & 7 & 9 & 1 & 3 \\
\hline $\mathrm{PM}(10)$ & 0.3333 & 1 & 3 & 5 & 7 & 0.3333 & 1 \\
\hline $\mathrm{PM}(2.5)$ & 0.2 & 0.3333 & 1 & 3 & 5 & 0.2 & 0.3333 \\
\hline $\mathrm{NO} 2$ & 0.1429 & 0.2 & 0.3333 & 1 & 3 & 0.1429 & 0.2 \\
\hline $\mathrm{CO}$ & 0.1111 & 0.1429 & 0.2 & 0.3333 & 1 & 0.1111 & 0.1429 \\
\hline Cost per sq ft & 1 & 3 & 5 & 7 & 9 & 1 & 3 \\
\hline $\begin{array}{l}\text { Distance from } \\
\text { business } \\
\text { centre }\end{array}$ & 0.3333 & 1 & 3 & 5 & 7 & 0.3333 & 1 \\
\hline
\end{tabular}

Table 4 represents the AHP matrix scaling based on the weight age criteria.

In AHP Matrix, the weight age for environment friendliness has been assigned based on the perception of people while, the weight ages for cost per sq.ft and distance from business centre have been allocated based on questionnaire.

Table 5 Weight age Matrix

\begin{tabular}{|l|l|}
\hline \multicolumn{2}{|c|}{ Weight age Matrix(A2) } \\
\hline $\mathrm{O} 2$ & 0.3018 \\
\hline $\mathrm{PM}(10)$ & 0.1377 \\
\hline $\mathrm{PM}(2.5)$ & 0.0658 \\
\hline $\mathrm{NO} 2$ & 0.0351 \\
\hline $\mathrm{CO}$ & 0.0202 \\
\hline Cost/sq ft & 0.3018 \\
\hline Distance from business centre & 0.1377 \\
\hline
\end{tabular}

Table 5 gives the weight age matrix

Table 6 Score Matrix

\begin{tabular}{|l|l|}
\hline \multicolumn{1}{|c|}{ Alternatives(Places) } & Score \\
\hline Katraj & 0.6421 \\
\hline Shivaji nagar & 0.5509 \\
\hline Pashan & 0.6757 \\
\hline Lohgaon & 0.6424 \\
\hline Manjri & 0.6898 \\
\hline Hadapsar & 0.5793 \\
\hline Alandi & 0.8416 \\
\hline
\end{tabular}

The score for given alternative is as shown in Table 6 . 


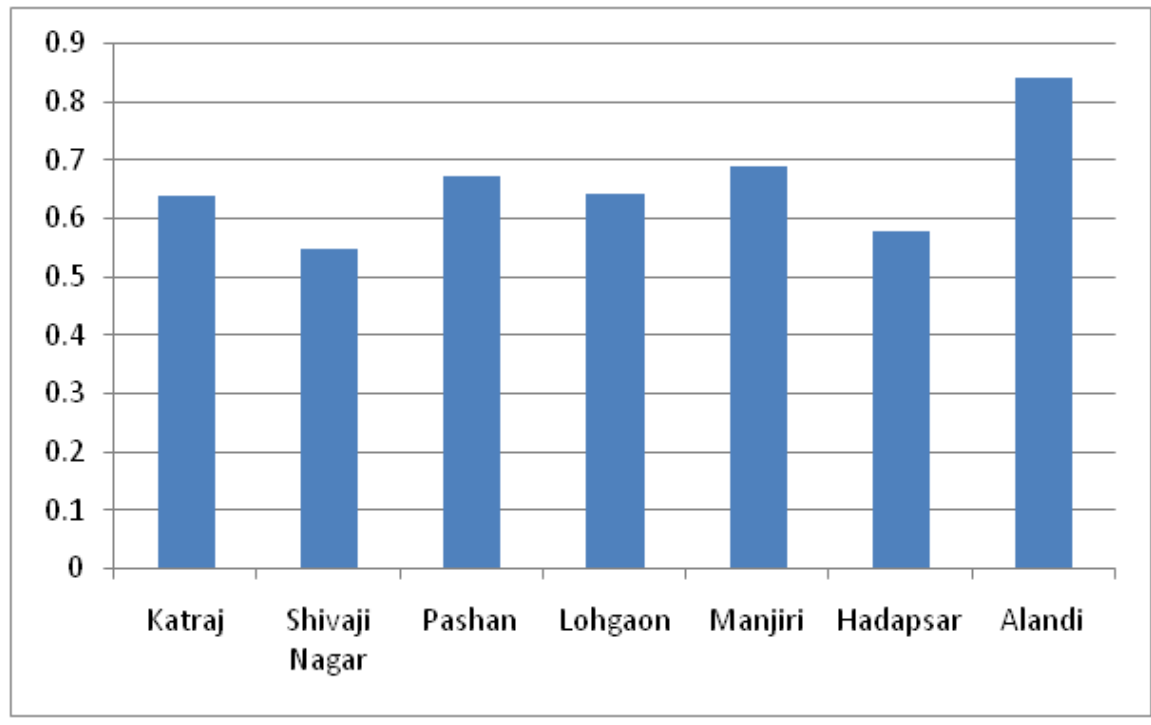

Graph 1 Relative score for alternatives.

Graph 1 shows the scores for the alternative places based on the study carried out.

Consistency can be checked using the help of Random Index values.

Table 7 Random Index Value

\begin{tabular}{|c|c|c|c|c|c|c|c|c|}
\hline Attributes & 3 & 4 & 5 & 6 & 7 & 8 & 9 & 10 \\
\hline RI & 0.52 & 0.89 & 1.11 & 1.25 & 1.35 & 1.4 & 1.45 & 1.49 \\
\hline
\end{tabular}

Table 7 shows the Random Index value

The consistency ratio is calculated using consistency index and random index

Consistency ratio $=$ consistency index/Random index .

The consistency ratio from the study is found to be $=0.037413<=0.1$

Hence, preference place is Alandi. Consistency ratio is also coming less than 0.1 hence this is the best solution we get out of the seven alternatives.

\section{CONCLUSION}

The study shows Alandi as the most feasible place to live if you prefer to live in environment friendly location. If we compare its distance from the working place it will be more. Alandi is also cost-effective location. Now a day a trend of work from home is mostly applied in software companies, In this case Alandi will be most preferable location for those who prefer to live in environment friendly location.

MCDM approach helps us to find the best solution among the number of alternatives present in the problem. AHP is giving a consistent solution near Pune city as is the main criteria, because most clients are coming from the Hinjewadi region.

\section{REFERENCES}

[1] Kardi Teknomo, Multi Criteria Decision Making, https://people.revoledu.com/kardi/tutorial/AHP/Multi-Criteria-Decision-Making.htm

[2] Ali Pahlavani (2010) A New Fuzzy MADM Approach and its Application to Project Selection Problem, International Journal of Computational Intelligence Systems, 3(1), 103-114, DOI: https://doi.org/10.1080/18756891.2010.9727681

[3] (2007). Introduction to Decision Making in the Manufacturing Environment. In: Decision Making in the Manufacturing Environment. Springer Series in Advanced Manufacturing. Springer, London. https://doi.org/10.1007/978-1-84628-819-7_1 
[4] https://en.wikipedia.org/wiki/Multi-criteria_decision_analysis

[5] Kuznetsov V, Fesenko G, Schwenk-Ferrero A, Andrianov A, Kuptsov I. Innovative Nuclear Energy Systems: State-of-the Art Survey on Evaluation and Aggregation Judgment Measures Applied to Performance Comparison. Energies. 2015; 8(5):3679-3719. https://doi.org/10.3390/en8053679

[6] M. Ravichandran and Dr. D. Suji, Container Traffic Projections Using AHP Model In Selecting Regional Transhipment Hub, International Journal of Civil Engineering and Technology, 7(2), 2016, pp. 185-192.

[7] D Bhanu Prakash, Dr. G Krishnaiah and N V S Shankar, Optimization of Process Parameters Using AHP and TOPSIS When Turning AISI 1040 Steel with Coated Tools. International Journal of Mechanical Engineering and Technology, 7(6), 2016, pp. 483-492.

[8] Assist. Prof. Mustafa Gersil. Importance of Packaging Waste Recycling Plants in Reverse Logistics and an Assessment of Plant Selection Using the AHP Method in Turkey. International Journal of Management, 7 (1), 2016, pp. 109-122. 